\section{The evolution of modern human brain shape}

\author{
Simon Neubauer,* Jean-Jacques Hublin, Philipp Gunz
}

Modern humans have large and globular brains that distinguish them from their extinct Homo relatives. The characteristic globularity develops during a prenatal and early postnatal period of rapid brain growth critical for neural wiring and cognitive development. However, it remains unknown when and how brain globularity evolved and how it relates to evolutionary brain size increase. On the basis of computed tomographic scans and geometric morphometric analyses, we analyzed endocranial casts of Homo sapiens fossils $(N=20)$ from different time periods. Our data show that, 300,000 years ago, brain size in early $H$. sapiens already fell within the range of present-day humans. Brain shape, however, evolved gradually within the $H$. sapiens lineage, reaching present-day human variation between about 100,000 and 35,000 years ago. This process started only after other key features of craniofacial morphology appeared modern and paralleled the emergence of behavioral modernity as seen from the archeological record. Our findings are consistent with important genetic changes affecting early brain development within the $H$. sapiens lineage since the origin of the species and before the transition to the Later Stone Age and the Upper Paleolithic that mark full behavioral modernity.

\section{INTRODUCTION}

Our ancestors' cognitive and behavioral abilities and the underlying brain morphology and function are critical for understanding the evolution of modern humans. Multiple lines of evidence from paleoanthropology, archeology, and genetics are informative about the evolution of brain and behavior in the Homo sapiens lineage, but there is no consensus about the tempo and mode of these biological and behavioral changes. In the absence of fossilized brains, we can study internal casts of the bony braincase. These endocasts approximate outer brain morphology because the brain, meninges, and cranial bones interact in an integrated and highly coordinated way during early development (1). Present-day modern humans have globular brains and globular endocasts with steep frontal, bulging parietal, and enlarged, rounded cerebellar areas. Together with small and retracted faces, this globularity characterizes the modern human skull (Fig. 1) (2,3). In contrast, Neandertals and other archaic Homo individuals have anterior-posteriorly elongated endocasts (4).

Ontogenetic data show that the adult endocranial shape differences between $H$. sapiens and Neandertals develop prenatally or during a perinatal globularization phase found only in the former group (5-8). Developmental globularization therefore occurs in a period of high brain growth rates and is largely driven by the brain (1). A large body of literature including clinical evidence shows that the tempo and mode of brain growth during this period are related to neural wiring underlying brain function and behavioral capabilities $(6,7,9-11)$. Developmental globularization leading to more globular brains in modern humans $(6,7)$ and differences in early brain growth rates leading to slightly larger adult brains in Neandertals (12) are consequently interesting in the discussion of brain evolution and related behavioral changes. Endocranial shape changes during later ontogeny (that is, after the eruption of the deciduous dentition) are similar among present-day humans, Neandertals, and great apes with only some adjustments in the amount of shape changes $(5-8,13,14)$. This shared segment of the ontogenetic pattern is thought to reflect interactions between the brain and the face, because the latter continues to grow after adult brain size has been achieved (5, 13-16).

Department of Human Evolution, Max Planck Institute for Evolutionary Anthropology, Deutscher Platz 6, 04103 Leipzig, Germany.

${ }^{*}$ Corresponding author. Email: simon.neubauer@eva.mpg.de
Hominin fossils from Jebel Irhoud (Morocco) that are associated with Middle Stone Age artifacts dated to around 300,000 years ago (17) display key features of modern human craniodental morphology including facial, mandibular, and dental characters comparable to later H. sapiens fossils or even present-day humans (18-20) as well as modern timing of dental development that suggests a human-like paced life history (21). Given these craniodental similarities, the Jebel Irhoud fossils are either interpreted as the currently earliest known members of the $H$. sapiens lineage $(3,20,22)$ or as part of an ancestral population related to the origin of $H$. sapiens (23). However, the braincases of the Jebel Irhoud fossils are not globular $(19,20,24)$. This demonstrates some independence of facial and neurocranial evolution in spite of important integration between these cranial modules via the cranial base (14-16). Together with other African fossils such as Omo Kibish [dated to around 195,000 years ago (25)], the Jebel Irhoud specimens force us to rethink the evolution of our species. Here, we therefore (i) investigate when and how the endocranial globularity typical of present-day modern humans emerged, (ii) analyze how this process is related to evolutionary brain size increase (4), and (iii) explore potential links between the evolution of the brain and genetic as well as behavioral changes.

Contrasting interpretations of the archeological record either see a rapid emergence of behavioral modernity at the transition to the Upper Paleolithic in Europe and the Later Stone Age in Africa possibly related to a mutation and consequently to neural changes ("human revolution" model) (26), or a gradual emergence as documented by the African Middle Stone Age without a specific biological correlate triggered by factors such as environmental changes or demographic developments (27). Features used to mark behavioral modernity range from worked bone, ornaments, pigments, and complex multicomponent lithic technologies to material indicators of manipulations of symbols and abstract thought such as unequivocal art. Some of those features are not exclusively known from modern human sites, and others are documented systematically only since the Upper Paleolithic (28).

Ancient DNA of archaic Homo representatives and H. sapiens fossils revealed derived genetic features that were fixed in $H$. sapiens after the population split from the clade including Neandertals and Denisovans more than 500,000 years ago (29-33). These genetic data suggest positive selection within our lineage on genes important for brain function and behavior and, especially, the development of the nervous system [for example, genes involved in axonal and dendritic growth or 

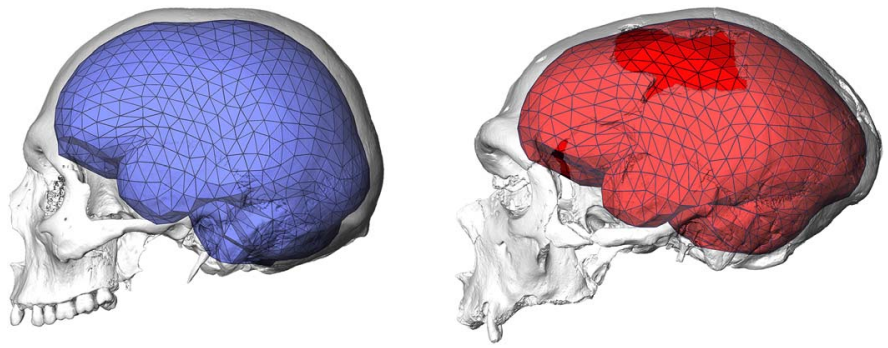

Fig. 1. Differences in brain shape between a present-day human (left, in blue) and a Neandertal from La Chapelle-aux-Saints (right, in red). Endocasts are shown together with the triangulated landmark set used in this study and $C T$ scan renderings of the crania.

synaptic transmission including NOVA1, SLITRK1, KATNA1, LUZP1, ARHGAP32, ADSL, HTR2B, and CNTNAP2 (30)]. Another example is FOXP2, a gene that is important for normal development of speech and language. Although amino acid substitutions specific to modern humans were also found in Neandertals, one substitution in an intron of this gene that affects a binding site for a transcription factor and likely alters the regulation of FOXP2 expression and associated behaviors is absent or polymorphic in Neandertals (31). On the other hand, a recent analysis showed that Neandertal genetic material that introgressed in the modern human lineage affects cranial and brain morphology of present-day humans (34).

Here, we analyzed endocasts of $H$. sapiens fossils from different geologic time periods. Previous quantitative analyses used smaller samples and were based on the endocranial midsagittal plane only (20), external landmarks only on the posterior neurocranium (19), or a set of some endocranial landmarks $(4,24)$. Here, we used geometric morphometrics based on three-dimensional coordinates of endocranial landmarks and hundreds of curve and surface semilandmarks $(5,35-37)$ measured on computed tomographic (CT) scans (fig. S1). We obtained landmark data for $20 \mathrm{H}$. sapiens fossils (Table 1 ) that can be divided into three groups according to geologic ages: (i) early $H$. sapiens from North and East Africa that lived about 300,000 to 200,000 years ago and therefore document the morphology of the currently earliest known representatives of our clade since the population split with Neandertals, (ii) Levantine and East African individuals that lived about 130,000 to 100,000 years ago, and (iii) Upper Paleolithic and geologically younger individuals that are about 35,000 to 10,000 years old. We compiled the same data for comparative samples of cranially diverse present-day humans from all over the world and archaic Homo representatives (Neandertals, Middle Pleistocene H. heidelbergensis sensu lato, and H. erectus sensu lato, as listed in Table 1) and computed Procrustes shape variables (see Materials and Methods). Incomplete and distorted fossils were reconstructed using established methods of computerassisted paleoanthropology [see Materials and Methods and previous studies $(36,38,39)]$.

\section{RESULTS}

\section{Variation of endocranial shape}

To explore endocranial shape variation of the H. sapiens fossils, we computed a between-group principal components analysis (bgPCA) of Procrustes shape variables. This space spans from the ancestral $H$. erectus shape to the derived shapes of Neandertals on the one hand and presentday humans on the other (Fig. 2 and fig. S2), according to the differences in species average endocranial shapes (fig. S3). The fuzzy borders of group convex hulls illustrate the uncertainty introduced by the reconstructions of incomplete fossils (see Materials and Methods). This reconstruction uncertainty does not alter the conclusions of our study. A multivariate shape regression on geologic age within archaic Homo individuals reveals a temporal trend from African $H$. erectus (H. ergaster) via Asian $H$. erectus to Neandertals (explained shape variance: $29.2 \%$; $P<0.01$ ). The Middle Pleistocene $H$. heidelbergensis sensu lato specimens Kabwe and Petralona plot along this temporal trend.

The earliest members of the H. sapiens clade (geologic age group 1) have endocranial shapes intermediate between $H$. erectus and Neandertals and seem to be part of the archaic temporal trend. Individuals of geologic age group 2 plot at the fringe of present-day humans, whereas the Upper Paleolithic and younger specimens (geologic age group 3) overlap with present-day human variation. Given the geologic age spans of age groups 2 and 3, the range of today's shape variation is therefore reached approximately between 100,000 and 35,000 years ago. H. sapiens fossils from different geologic time periods therefore capture evolutionary shape changes leading to the globular endocranial shape of present-day humans. A multivariate regression of endocranial shape on geologic age explains $21.9 \%$ of shape variance $(P<0.01)$ and corresponds to a change from an elongated to a globular shape: From geologically older to younger H. sapiens, the frontal area becomes taller, the parietal areas bulge, the side walls become parallel, and the occipital area becomes rounder and less overhanging. Moreover, the cerebellum becomes relatively larger and more bulging, the cranial base more flexed, and the temporal poles narrower and oriented anterior-medially (Fig. 3 and movies S1 to S3). Colorcoding areas of size increase reveals that parietal bulging is not associated with an increase of the parietal surface but that cerebellar bulging is (Fig. 3 and fig. S4A). Both processes contribute to increased globularity. In addition to the PCA and regression analysis, we also visualized evolutionary globularization in $H$. sapiens as changes between the mean shapes of geologic age groups (fig. S4, B and C). Endocranial shape changes from geologic age group 1 to geologic age group 2 are associated with size increase in cerebellar and lateral parietotemporal areas. In the second step (geologic age group 2 to 3 ), shape changes are associated with size increase primarily in cerebellar and occipital areas. The shape changes associated with both steps contribute to globularization in $\mathrm{H}$. sapiens. The trajectory from $H$. erectus to Neandertals reveals a contrasting pattern: The cerebrum increases in size in relationship to the cranial base (fig. S4, D and E).

Notably, the overarching pattern of globularization in H. sapiens is not related to geographic variation but represents a general temporal trend:The North and East African specimens of geologic age group 1 have similar endocranial shapes, the East African specimen Laetoli Hominid (L.H.) 18 clusters with the contemporaneous Levantine individuals (geologic age group 2), the Hofmeyr endocast from South Africa, and the Levantine individual Ohalo II $\mathrm{H} 2$ group with the European specimens of comparable ages (geologic age group 3) (fig. S2).

\section{Relationship of endocranial shape and size}

To explore whether globularization helped overcome constraints on encephalization, we computed a bgPCA in form space that allows interpreting allometric relationships. The first PC of form space (Fig. 4 and fig. S5) is highly correlated to size variation $(R=0.98)$ and, as expected, separates $H$. erectus from Neandertals and present-day humans. Although endocranial form of $H$. sapiens fossils demonstrates a temporal trend toward present-day human variation, their size variation overlaps among all geologic age groups of $H$. sapiens fossils, as well as with the size variation in present-day humans and Neandertals (Fig. 4 and fig. S5). This finding is mirrored by endocranial volume estimates of our fossil 
Table 1. Sample of $\boldsymbol{H}$. sapiens fossils and comparative samples. Geologic ages used for regression analyses [in thousand years (ky)] were based on estimates in published literatures (references available upon request). Endocranial volume estimates of this study with SD of multiple estimates.

\section{H. sapiens fossils}

\section{Geologic age group 1}

\begin{tabular}{|c|c|c|}
\hline Jebel Irhoud 1 & 315 ky & $1.375 \pm 6 \mathrm{ml}$ \\
\hline Jebel Irhoud 2 & 315 ky & $1.467 \pm 6 \mathrm{ml}$ \\
\hline Omo 2 & 195 ky & $1.491 \pm 4 \mathrm{ml}$ \\
\hline
\end{tabular}

Geologic age group 2

\begin{tabular}{|ccc}
\hline L.H. 18 & $120 \mathrm{ky}$ & $1.237 \pm 5 \mathrm{ml}$ \\
\hline Skhul V & $115 \mathrm{ky}$ & $1.363 \pm 1 \mathrm{ml}$ \\
\hline Qafzeh 6 & $115 \mathrm{ky}$ & $1.524 \pm 8 \mathrm{ml}$ \\
\hline Qafzeh 9 & $115 \mathrm{ky}$ & $1.497 \pm 5 \mathrm{ml}$ \\
\hline Geologic age group 3 & & \\
\hline Hofmeyr & $36 \mathrm{ky}$ & $1.498 \pm 13 \mathrm{ml}$ \\
\hline Mladeč 1 & $35 \mathrm{ky}$ & $1.606 \mathrm{ml}$ \\
\hline Cro-Magnon 1 & $31 \mathrm{ky}$ & $1.574 \pm 1 \mathrm{ml}$ \\
\hline Cro-Magnon 3 & $31 \mathrm{ky}$ & $1.813 \pm 32 \mathrm{ml}$ \\
\hline Dolní Věstonice 16 & $30 \mathrm{ky}$ & $1.542 \pm 4 \mathrm{ml}$ \\
\hline Dolní Věstonice 13 & $29 \mathrm{ky}$ & $1.590 \pm 2 \mathrm{ml}$ \\
\hline Dolní Věstonice 14 & $29 \mathrm{ky}$ & $1.663 \pm 5 \mathrm{ml}$ \\
\hline Dolní Věstonice 15 & $29 \mathrm{ky}$ & $1.385 \pm 3 \mathrm{ml}$ \\
\hline Abri Pataud & $27 \mathrm{ky}$ & $1.323 \mathrm{ml}$ \\
\hline Ohalo II H2 & $22 \mathrm{ky}$ & $1.475 \pm 1 \mathrm{ml}$ \\
\hline Oberkassel D999 & $14 \mathrm{ky}$ & $1.330 \pm 2 \mathrm{ml}$ \\
\hline Oberkassel D99 & $13 \mathrm{ky}$ & $1.492 \mathrm{ml}$ \\
\hline Combe Capelle & $8 \mathrm{ky}$ & $1.457 \pm 2 \mathrm{ml}$ \\
\hline
\end{tabular}

Present-day humans

89 cranially diverse present-day humans

\section{Neandertals}

\begin{tabular}{|c|c|c|}
\hline Gibraltar 1 & 75 ky & $1213 \pm 4 \mathrm{ml}$ \\
\hline La Ferrassie 1 & 70 ky & $1643 \pm 5 \mathrm{ml}$ \\
\hline Guattari & 55 ky & $1421 \pm 3 \mathrm{ml}$ \\
\hline Amud 1 & 53 ky & $1747 \pm 16 \mathrm{ml}$ \\
\hline La Chapelle-aux-Saints & 52 ky & $1490 \pm 3 \mathrm{ml}$ \\
\hline Feldhofer 1 & 40 ky & $1261 \pm 28 \mathrm{ml}$ \\
\hline Spy I & 40 ky & $1287 \pm 9 \mathrm{ml}$ \\
\hline Spy II & 40 ky & $1531 \pm 7 \mathrm{ml}$ \\
\hline
\end{tabular}

\section{H. heidelbergensis sensu lato}

\begin{tabular}{|c|c|c|}
\hline Kabwe & $600-250 \mathrm{ky?}$ & $1249 \mathrm{ml}$ \\
\hline Petralona & $400-150$ ky? & $1162 \pm 2 \mathrm{ml}$ \\
\hline \multicolumn{3}{|l|}{ H. erectus sensu lato } \\
\hline KNM-ER 3733 & 1780 ky & $878 \pm 2 \mathrm{ml}$ \\
\hline KNM-ER 3833 & $1570 \mathrm{ky}$ & $838 \pm 1 \mathrm{ml}$ \\
\hline KNM-WT 15000 & 1535 ky & $850 \pm 4 \mathrm{ml}$ \\
\hline $\mathrm{OH} 9$ & 1470 ky & $1013 \pm 4 \mathrm{ml}$ \\
\hline Sangiran 2 & 1500 ky & $793 \pm 4 \mathrm{ml}$ \\
\hline Sambungmacan 3 & $200 \mathrm{ky}$ & $902 \pm 4 \mathrm{ml}$ \\
\hline Ngandong 14 & 200 ky & $1127 \pm 2 \mathrm{ml}$ \\
\hline Ngawi & 200 ky & $952 \pm 1 \mathrm{ml}$ \\
\hline
\end{tabular}

reconstructions (Table 1 ). The endocranial volumes of early $H$. sapiens individuals (Jebel Irhoud 1, $1375 \pm 6 \mathrm{ml}$; Jebel Irhoud 2, $1467 \pm 6 \mathrm{ml}$; Omo 2, $1491 \pm 4 \mathrm{ml}$ ) fall within the range of our samples of present-day humans (mean, $1328 \mathrm{ml}$; SD, $164 \mathrm{ml}$ ) and Neandertals (mean, $1450 \mathrm{ml}$; $\mathrm{SD}, 189 \mathrm{ml}$ ) and are considerably larger than those of our $H$. erectus sample (mean, $919 \mathrm{ml}$; SD, $108 \mathrm{ml}$ ).

In archaic Homo individuals, endocranial size and geologic age are negatively correlated $(R=-0.84)$, and size explains a similar amount of variance as geologic age (multivariate shape regression on the logarithm of centroid size; explained shape variance: $24.4 \% ; P<0.01$ ). Visualizations of this allometric regression (figs. S4, D and E, and S6, and movies S4 to S6) reveal shape changes that differ from the temporal trend within H. sapiens in an important way: Overall, archaic Homo individuals maintain an elongated endocast along the allometric regression. With increases in endocranial size, the cerebrum gets enlarged on top of the brain stem and cerebellum.

In contrast to archaic Homo, geologic age and size are not correlated in $H$. sapiens fossils $(R=-0.02)$, and size does not account for endocranial shape variation (multivariate shape regression on the logarithm of centroid size; explained shape variance: $4.8 \% ; P=0.99$ ). This finding is also expressed by nearly orthogonal regression lines of the temporal and the allometric trend in the first two PCs of form space (Fig. 4).

\section{DISCUSSION}

\section{The brain of early $H$. sapiens}

In line with genetic data (32) that suggest a population split between modern humans on the one hand and Neandertals and Denisovans on the other more than 500,000 years ago, we view H. sapiens as an evolving lineage with deep African roots. Our results, in combination with evidence from craniofacial morphology $(18-20,22)$ and dental development (21), suggest that modern human brain shape was not established at the origin of our species together with other key features of craniodental morphology: Our analyses confirm that early H. sapiens [geologic age group 1, that is, not only Jebel Irhoud individuals but also the geologically younger, presumably 195,000-year-old (25) specimen Omo 2] did not have globular brains $(19,20,24)$. Instead, they had shapes intermediate between $H$. erectus and Neandertals. Yet, the size of their brain was already substantially larger than that in H. erectus 


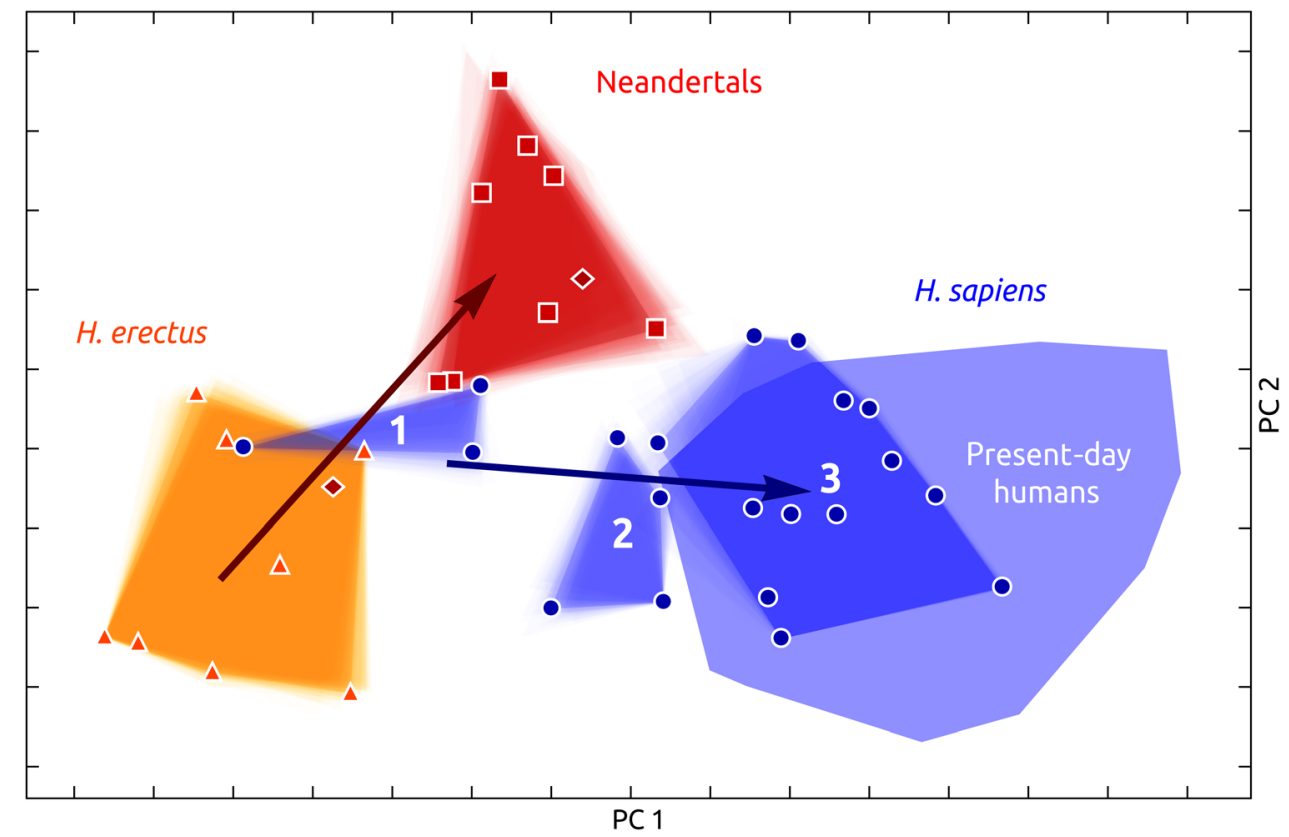

Fig. 2. bgPCA of endocranial shape. H. erectus, triangles and orange convex hull; Neandertals, squares and red convex hull; H. heidelbergensis/rhodesiensis, dark red diamonds; present-day humans, light blue convex hull; H. sapiens fossils, circles and dark blue convex hulls for geologic age groups 1 to 3 . Evolutionary trends of shape changes in archaic and modern individuals are shown as regressions on geologic age (arrows) (see fig. S2 for labels of fossil individuals).

(at the upper boundary of $H$. heidelbergensis sensu lato) and in the range of geologically younger $H$. sapiens fossils and present-day humans (40). We therefore suggest that early members of the H. sapiens lineage initially attained large brains via the archaic allometric pathway (4) and only subsequently diverged from this pattern to evolve the globular brain characteristic of present-day humans. Some authors have challenged the interpretation of the Jebel Irhoud hominins as early H. sapiens (20) and view them instead as ancestral to $H$. sapiens (23). However, we note that our interpretation is robust against the species label attached to the Jebel Irhoud fossils (and by extension also to Omo 2) and that later H. sapiens individuals from geologic age group 2 still do not exhibit present-day human-like brain globularity (see Discussion below). Two fossils also related to the origin of our species [Omo 1 and the approximately 260,000-year-old Florisbad specimen (41)] are unfortunately too fragmentary to be included in the analysis.

\section{Gradual globularization within $\boldsymbol{H}$. sapiens}

Indisputable $H$. sapiens individuals from about 130,000 to 100,000 years ago (geologic age group 2) have more globular brains than the earliest H. sapiens fossils and are more similar to, but still different from, present-day humans. H. sapiens individuals that are younger than about 35,000 years (geologic age group 3) overlap with the range of variation in present-day humans. Our analyses therefore demonstrate that the evolution of modern human brain shape is characterized by directional and gradual changes resulting in the typical globular modern human shape established at some point after about 100,000 years ago and probably before 35,000 years ago. We expect that future analyses based on additional fossil specimens filling the temporal gaps between our geologic age groups will further elucidate the mode of evolutionary shape change and help to pinpoint the exact time when present-day human brain shape was established. Unfortunately, no CT data of the Herto skull (BOU-VP-16/1) dated to about 160,000 years old (42) were available for this study. If this specimen exhibits an endocranial shape intermediate between the mean shapes of geologic age groups 1 and 2 (fig. S4, B and C), then this will further strengthen our hypothesis of a gradual emergence of present-day human globularity.

Investigating brain shape changes as a two-step process between our three geologic age groups suggests some variation in the overarching gradual pattern of globularization. Although both steps include parietal and cerebellar bulging, it is interesting to note that the first step (from geologic age group 1 to geologic age group 2 ) includes only subtle shape changes of brain regions associated with the anterior and middle cranial fossae. Because this part of the cranial base acts as the interface between the brain and the face, this suggests that the initial globularization was driven by changes in brain organization and not by changes in facial size and shape. The second step of globularization (from geologic age group 2 to 3) also comprises shape changes in these regions, suggesting that integration of the endocranium with the face might have contributed to endocranial globularization (14) but only in later phases of $H$. sapiens evolution.

\section{Implications of evolutionary globularization}

Evolutionary brain globularization in $H$. sapiens corresponds to the shape changes during the developmental globularization phase found in present-day humans $(5,43)$. In light of the documented differences between the ontogenetic patterns in present-day humans, Neandertals, and great apes $(5-8,13,14,43)$, we suggest that this evolutionary globularization is linked to a gradual evolution of the developmental globularization phase and therefore caused by changes to perinatal brain development.

Two features of this process stand out: parietal and cerebellar bulging. Parietal areas are involved in orientation, attention, perception of stimuli, sensorimotor transformations underlying planning, visuospatial integration, imagery, self-awareness, working and long-term memory, numerical processing, and tool use (44-49). Because parietal bulging is not associated with an increase of outer parietal surface area [mirroring 

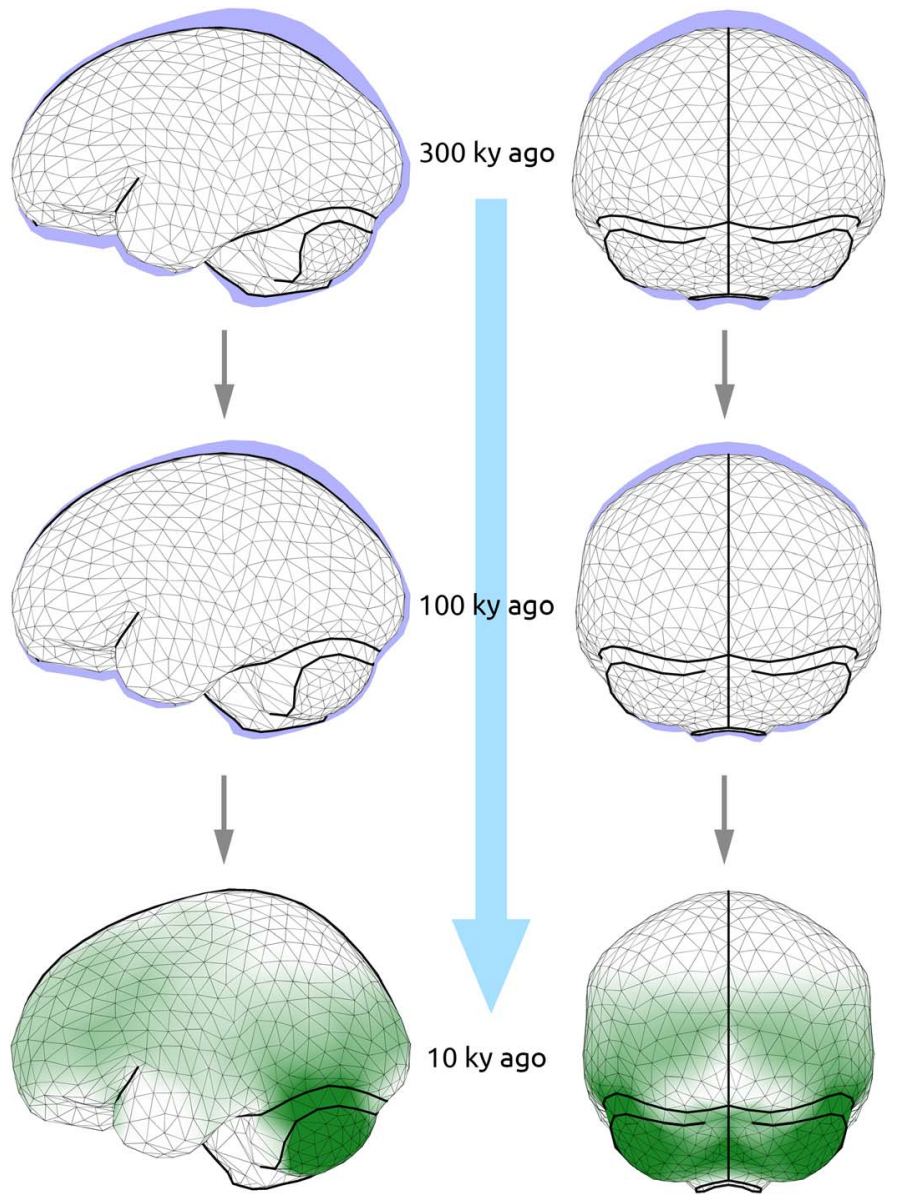

Fig. 3. Gradual evolutionary changes of endocranial shape within $H$. sapiens fossils shown as a series of predicted shapes according to the regression on geologic age at $\mathbf{3 0 0 , 0 0 0}$ years ago (top), 100,000 years ago (middle), and 10,000 years ago (bottom and blue area in top and middle). Color coding in green (bottom) illustrates regions with surface size increase associated with this gradual shape changes. Lateral (left) and occipital (right) views (see also fig. S4 and movies S1 to S3). ontogeny (43)], it is likely that a size increase of regions that are not visible on the external surface of the brain is responsible for parietal bulging. For example, the precuneus is hidden in the interhemispheric fissure and was shown to be larger in humans than in chimpanzees (49). Furthermore, parietal bulging in present-day humans has been linked to large shape variation in the precuneus $(50,51)$. The precuneus is a central node of the default-mode network and an important hub of brain organization. Bruner et al. (49) therefore concluded that precuneus expansion in $H$. sapiens is related to cognitive specializations.

The cerebellum is associated not only with motor-related functions like the coordination of movements and balance but also with spatial processing, working memory, language, social cognition, and affective processing (52-55). The developmental and evolutionary shape changes of the posterior cranial fossa are linked to the rapid cerebellar expansion during perinatal brain growth. Clinical neuroimaging data from modern humans show that in the first 3 months of life, the cerebellum grows at the highest rate of all brain parts (more than doubling in 90 days) (56). The cerebellum is frequently implied in childhood onset disorders and known to be vulnerable to environmental influences during early childhood (57).

It is intriguing that the evolutionary brain globularization in H. sapiens parallels the emergence of behavioral modernity documented by the archeological record. First, the emergence of the Middle Stone Age is close in time to the currently earliest known fossils of early $H$. sapiens (17) that had large brains but did not exhibit any major changes to (outer) brain morphology (20). Second, as the H. sapiens brain gradually became more globular, features of behavioral modernity accumulated gradually with time (27). Third, at the time when brain globularity of our ancestors fell within the range of variation of present-day humans, the full set of features of behavioral modernity had accumulated at the transition from the Middle to the Later Stone Age in Africa and from the Middle to the Upper Paleolithic in Europe around 50,000 to 40,000 years ago (26). In this context, the "human revolution" just marks the point in time when gradual changes reach full modern behavior and morphology and does not represent a rapid evolutionary event related to only one important genetic change that leads to a rapid emergence of modern human brain morphology and behavioral modernity.

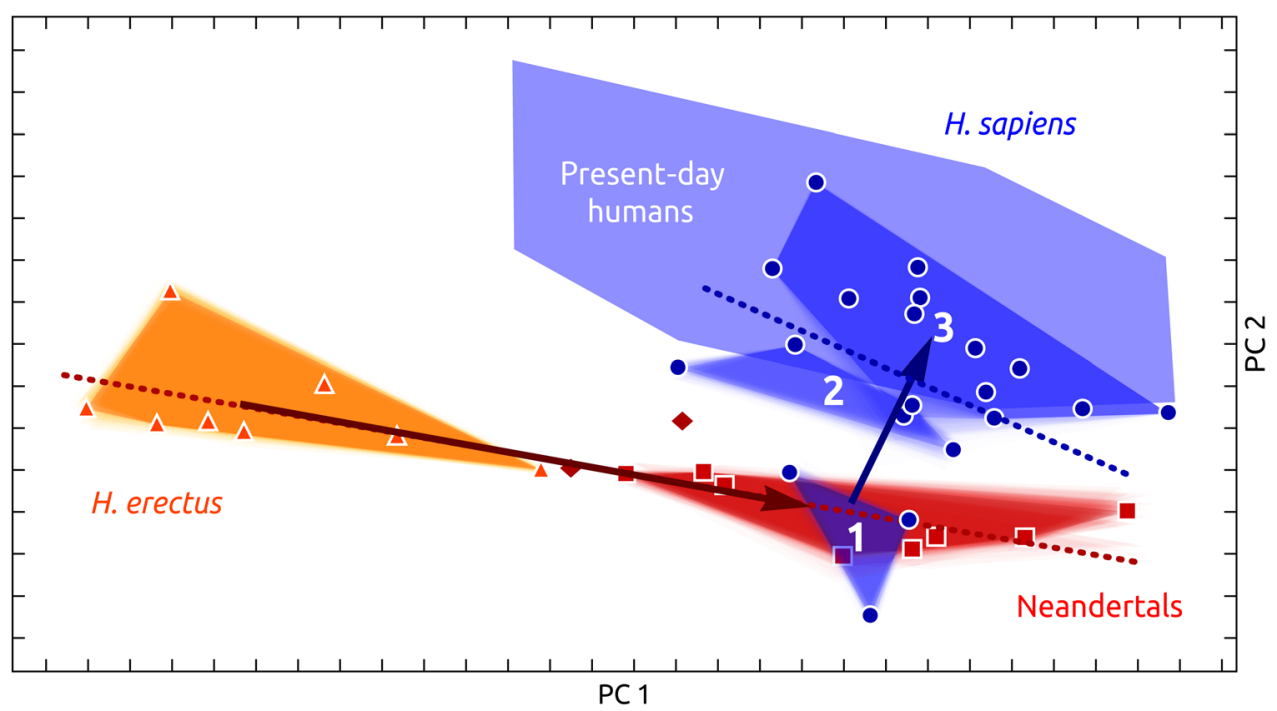

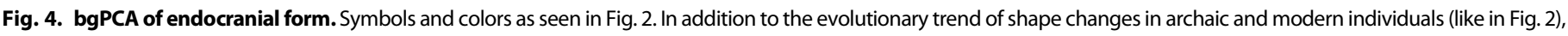
allometric relationships are shown as regressions on centroid size (dotted lines) (see fig. S5 for labels of fossil individuals). 
Gene drift theoretically could have caused the morphological changes in the $H$. sapiens lineage in a lengthy process of modern human origins (58), but genetic data based on ancient DNA suggest positive selection of several genes important for nervous system development, brain function, and behavior in our lineage including genes involved in axonal and dendritic growth or synaptic transmission (29-33). According to the parallels between the emergence of anatomical and behavioral modernity, some of these genes were selected and fixed at different times since the origin of our species and before the transition to the Upper Paleolithic. Any changes of brain-related genes at the origin of our species did not affect outer brain morphology and are therefore not recorded in the shape of the endocranium. Neandertals and their ancestors might have acquired some, but not all, modern behaviors (28) with a brain that became large via the archaic allometric pathway (4).

\section{CONCLUSIONS}

Our data suggest that the evolution of modern human brain shape was characterized by a directional, gradual change. The gradual emergence of both behavioral modernity in the archeological record (27) and brain globularity in $H$. sapiens fossils suggests that evolutionary changes to early brain development $(6,7,9-11)$ were critical for the evolution of morphology and behavior of our species. Our findings are consistent with the fixation of genes related to brain development (29-33) within the H. sapiens lineage.

\section{MATERIALS AND METHODS}

\section{Sample, CT scans, and landmark data}

Our sample consisted of $20 \mathrm{H}$. sapiens fossils with various geologic ages from about 300,000 to 10,000 years ago, $8 \mathrm{H}$. erectus individuals, 8 Neandertals, 2 other Middle Pleistocene Homo individuals (Kabwe and Petralona), and 89 cranially diverse present-day humans from all over the world (Table 1). All individuals were CT-scanned to get nondestructive access to the endocranium. All measurements were collected from the digital data.

We generated digital endocasts on the basis of the CT scans and measured 935 endocranial landmarks and sliding semilandmarks on endocranial curves and the endocranial surface to capture the overall shape of the endocasts (Fig. 1 and fig. S1). Semilandmarks were allowed to slide along tangents to the curves and the surface so as to minimize bending energy. Thereby, semilandmarks can be treated as geometrically homologous within this sample $(35,59)$. Data preparation and the measurement protocol are detailed in previous studies of Neubauer and co-workers $(5,43)$.

Landmark configurations were symmetrized using the mean of the original and reflected relabeled version $(36,37)$ and then superimposed the symmetrized data using generalized least-squares Procrustes analysis to remove nonshape information about location and orientation from the raw coordinates and to scale each individual to unit centroid size. The remaining Procrustes shape variables and centroid sizes were analyzed.

\section{Fossil reconstruction}

Incomplete and/or distorted fossil individuals were reconstructed in the following well-established way: (i) Where possible, bony fragments were realigned according to smoothness criteria and anatomical knowledge and fragments preserved on only one side were mirror-imaged to the other side; (ii) partial digital endocasts were generated; (iii) coordinates of preserved endocranial landmarks and semilandmarks were obtained; (iv) missing landmarks and semilandmarks were estimated on the basis of a thin-plate spline interpolation of a reference individual $(35,36,38,39)$. Instead of using only one reference individual, we used the entire sample of present-day humans and fossil individuals, resulting in 126 reconstructions for every incomplete fossil. For Hofmeyr, we used only reconstructions based on present-day humans because, given for the missing regions of this individual, other reconstructions were not reasonable. For Cro-Magnon 3 and Feldhofer 1, which lack very large, connected areas (the entire endocranial base), the validity of thin-plate spline reconstructions was questionable. We therefore used multiple multivariate regressions to estimate the missing regions (36). For all other individuals with missing data, this alternative means of reconstruction largely conforms to the thin-plate spline reconstructions.

\section{Statistical analysis}

We computed a bgPCA in shape space on the basis of the mean shapes of $H$. erectus, Neandertals, and present-day humans. bgPCA is an ordination technique that highlights differences between groups and, at the same time, is not biased by differences in sample sizes among groups and preserves the real, undistorted shape distances between groups. We then projected all individuals into this space including the $H$. sapiens fossils and explored their shape in this morphospace that spans from the ancestral $H$. erectus shape to the derived shapes of Neandertals and present-day humans. Geologic ages of the fossils are not part of the data to compute this morphospace, but geologic age information attached to the fossils allows interpreting possible temporal trends within H. sapiens fossils. Convex hulls were used to delineate group variation. We randomly sampled one of the 126 reconstructions for each fossil of a given group, plotted transparent convex hulls, and repeated this 100 times. The resulting lighter, fuzzy borders of convex hulls illustrate that reconstruction uncertainties of the fossils affect group variation only to a low extent and that reconstruction uncertainties do not affect the interpretation of the results.

Furthermore, we computed a bgPCA in form space to investigate allometric relationships during evolution. To further analyze temporal trends within $H$. sapiens fossils and among the archaic fossils (not including Kabwe and Petralona for which geologic ages are highly uncertain), we computed multivariate shape regressions on geologic age and the percentage of shape variance explained by geologic age. Geologic age information was extracted from published estimates and, if required for ${ }^{14} \mathrm{C}$ data, was calibrated according to CALIB 7.1. We tested the significance of this regression by permuting the geologic ages of $H$. sapiens fossils, recalculating the regression, and repeating this for 1000 times. We did the same to investigate relationships between endocranial size and shape within $H$. sapiens fossils and among the archaic fossils. Geologic ages and centroid sizes were logged for these computations. Furthermore, we visualized shape differences and shape changes along regression slopes as triangulations of the landmarks and semilandmarks. It is important to emphasize here that we did not compute regressions of single PCs on endocranial size or geologic age but multivariate regressions based on all shape variables (the Procrustes shape variables are the dependent variables, whereas age and size are the independent variables). These regressions were visualized as shape changes (Fig. 3, fig. S6, and movies S1 to S6) in real space and visualized in shape space (Fig. 2) and form space (Fig. 4) as arrows. To investigate endocranial shape changes independently from PCA and regression analysis, we visualized evolutionary shape changes as a two-step process: the shape differences between geologic age groups 1 and 2 and the differences between geologic age groups 2 and 3). We also color-coded 
regions of surface area difference to highlight which of the shape changes are associated to an increase in size (43).

To obtain endocranial volume estimates for reconstructed fossils, we computed the volume of the triangulated symmetrized landmark set for each of the multiple reconstructions and computed a mean and SD. For Cro-Magnon 3 and Feldhofer 1, volume estimates were 1790 and 1269 $\mathrm{ml}$, respectively, when based on a multivariate regression, whereas values listed in Table 1 were based on multiple reconstructions. Variation among multiple reconstructions can be interpreted as uncertainty of the endocranial volume estimate. Because a triangulation of 935 (semi)landmarks only approximates the endocranial surface and therefore underestimates the endocranial volume as measured from the CT scans or the actual individual, we added a correction scalar of $23 \mathrm{ml}$, which is the mean residual of a regression of measured versus computed endocranial volumes in the present-day human sample without missing data for which both, a volume computed as described here and a volume as measured from a segmented endocast, were available.

\section{SUPPLEMENTARY MATERIALS}

Supplementary material for this article is available at http://advances.sciencemag.org/cgi/ content/full/4/1/eaao5961/DC1

fig. S1. Landmark set used in this study.

fig. S2. bgPCA of endocranial shape.

fig. S3. Average endocranial shapes of $H$. erectus, Neandertals, and present-day humans that the bgPCA is based on.

fig. S4. Visualization of surface area expansion associated with shape changes.

fig. S5. bgPCA of endocranial form.

fig. S6. Allometric relationships within archaic Homo representatives shown as a series of predicted shapes according to the regression on size.

movie S1. Brain shape evolution in $H$. sapiens (lateral view).

movie S2. Brain shape evolution in H. sapiens (occipital view).

movie S3. Brain shape evolution in $H$. sapiens (inferior view).

movie S4. Brain shape allometry in archaic Homo representatives (lateral view).

movie S5. Brain shape allometry in archaic Homo representatives (occipital view).

movie S6. Brain shape allometry in archaic Homo representatives (inferior view).

\section{REFERENCES AND NOTES}

1. M. L. Moss, R. W. Young, A functional approach to craniology. Am. J. Phys. Anthropol. 18, 281-292 (1960).

2. D. E. Lieberman, B. M. McBratney, G. Krovitz, The evolution and development of cranial form in Homo sapiens. Proc. Natl. Acad. Sci. U.S.A. 99, 1134-1139 (2002).

3. C. Stringer, The origin and evolution of Homo sapiens. Philos. Trans. R. Soc. Lond. B Biol. Sci. 371, 20150237 (2016).

4. E. Bruner, G. Manzi, J. L. Arsuaga, Encephalization and allometric trajectories in the genus Homo: Evidence from the Neandertal and modern lineages. Proc. Natl. Acad. Sci. U.S.A. 100, 15335-15340 (2003).

5. S. Neubauer, P. Gunz, J.-J. Hublin, Endocranial shape changes during growth in chimpanzees and humans: A morphometric analysis of unique and shared aspects. J. Hum. Evol. 59, 555-566 (2010).

6. P. Gunz, S. Neubauer, B. Maureille, J.-J. Hublin, Brain development after birth differs between Neanderthals and modern humans. Curr. Biol. 20, R921-R922 (2010).

7. P. Gunz, S. Neubauer, L. Golovanova, V. Doronichev, B. Maureille, J.-J. Hublin, A uniquely modern human pattern of endocranial development. Insights from a new cranial reconstruction of the Neandertal newborn from Mezmaiskaya. J. Hum. Evol. 62, 300-313 (2012).

8. M. S. Ponce de León, T. Bienvenu, T. Akazawa, C. P. E. Zollikofer, Brain development is similar in Neanderthals and modern humans. Curr. Biol. 26, R665-R666 (2016).

9. E. Courchesne, K. Pierce, C. M. Schumann, E. Redcay, J. A. Buckwalter, D. P. Kennedy, J. Morgan, Mapping early brain development in autism. Neuron $\mathbf{5 6}$ 399-413 (2007).

10. E. Courchesne, P. R. Mouton, M. E. Calhoun, K. Semendeferi, C. Ahrens-Barbeau, M. J. Hallet, C. C. Barnes, K. Pierce, Neuron number and size in prefrontal cortex of children with autism. JAMA 306, 2001-2010 (2011).

11. C. Boeckx, A. Benítez-Burraco, The shape of the human language-ready brain Front. Psychol. 5, 282 (2014).
12. M. S. Ponce de León, L. Golovanova, V. Doronichev, G. Romanova, T. Akazawa, O. Kondo, H. Ishida, C. P. E. Zollikofer, Neanderthal brain size at birth provides insights into the evolution of human life history. Proc. Natl. Acad. Sci. U.S.A. 105, 13764-13768 (2008).

13. N. Scott, S. Neubauer, J. -J. Hublin, P. Gunz, A shared pattern of postnatal endocranial development in extant hominoids. Evol. Biol. 41, 572-594 (2014).

14. C. P. E. Zollikofer, T. Bienvenu, M. S. Ponce de León, Effects of cranial integration on hominid endocranial shape. J. Anat. 230, 85-105 (2017).

15. D. E. Lieberman, O. M. Pearson, K. M. Mowbray, Basicranial influence on overall cranial shape. J. Hum. Evol. 38, 291-315 (2000).

16. M. Bastir, A. Rosas, C. Stringer, J. Manuel Cuétara, R. Kruszynski, G. W. Weber, C. F. Ross, M. J. Ravosa, Effects of brain and facial size on basicranial form in human and primate evolution. J. Hum. Evol. 58, 424-431 (2010).

17. D. Richter, R. Grün, R. Joannes-Boyau, T. E. Steele, F. Amani, M. Rué, P. Fernandes, J.-P. Raynal, D. Geraads, A. Ben-Ncer, J.-J. Hublin, S. McPherron, The age of the hominin fossils from Jebel Irhoud, Morocco, and the origins of the Middle Stone Age. Nature 546, 293-296 (2017).

18. S. E. Freidline, P. Gunz, K. Harvati, J.-J. Hublin, Middle Pleistocene human facial morphology in an evolutionary and developmental context. J. Hum. Evol. 63, 723-740 (2012).

19. K. Harvati, J.-J. Hublin, P. Gunz, Evolution of middle-late Pleistocene human cranio-facial form: A 3-D approach. J. Hum. Evol. 59, 445-464 (2010).

20. J.-J. Hublin, A. Ben-Ncer, S. E. Bailey, S. E. Freidline, S. Neubauer, M. M. Skinner, I. Bergmann, A. Le Cabec, S. Benazzi, K. Harvati, P. Gunz, New fossils from Jebel Irhoud Morocco and the pan-African origin of Homo sapiens. Nature 546, 289-292 (2017).

21. T. M. Smith, P. Tafforeau, D. J. Reid, R. Grün, S. Eggins, M. Boutakiout, J.-J. Hublin, Earliest evidence of modern human life history in North African early Homo sapiens. Proc. Natl. Acad. Sci. U.S.A. 104, 6128-6133 (2007).

22. C. Stringer, J. Galway-Witham, Palaeoanthropology: On the origin of our species. Nature 546, 212-214 (2017).

23. J. M. Bermúdez de Castro, M. Martinón-Torres, J. L. Arsuaga, E. Carbonell, Twentieth anniversary of Homo antecessor (1997-2017): A review. Evol. Anthropol. 26, 157-171 (2017).

24. E. Bruner, O. Pearson, Neurocranial evolution in modern humans: The case of Jebel Irhoud 1. Anthropol. Sci. 121, 31-41 (2012).

25. I. McDougall, F. H. Brown, J. G. Fleagle, Stratigraphic placement and age of modern humans from Kibish, Ethiopia. Nature 433, 733-736 (2005).

26. R. G. Klein, Archeology and the evolution of human behavior. Evol. Anthropol. 9, 17-36 (2000).

27. S. Mcbrearty, A. S. Brooks, The revolution that wasn't: A new interpretation of the origin of modern human behavior. J. Hum. Evol. 39, 453-563 (2000).

28. W. Roebroeks, M. Soressi, Neandertals revised. Proc. Natl. Acad. Sci. U.S.A. 113, 6372-6379 (2016).

29. R. E. Green, J. Krause, A. W. Briggs, T. Maricic, U. Stenzel, M. Kircher, N. Patterson, H. Li, W. Zhai, M. H.-Y. Fritz, N. F. Hansen, E. Y. Durand, A.-S. Malaspinas, J. D. Jensen, T. Marques-Bonet, C. Alkan, K. Prüfer, M. Meyer, H. A. Burbano, J. M. Good, R. Schultz, A. Aximu-Petri, A. Butthof, B. Höber, B. Höffner, M. Siegemund, A. Weihmann, C. Nusbaum, E. S. Lander, C. Russ, N. Novod, J. Affourtit, M. Egholm, C. Verna, P. Rudan, D. Brajkovic, Ž. Kucan, I. Gušic, V. B. Doronichev, L. V. Golovanova, C. Lalueza-Fox, M. de la Rasilla, J. Fortea, A. Rosas, R. W. Schmitz, P. L. F. Johnson, E. E. Eichler, D. Falush, E. Birney, J. C. Mullikin, M. Slatkin, R. Nielsen, J. Kelso, M. Lachmann, D. Reich, S. Pääbo, A draft sequence of the Neandertal genome. Science 328, 710-722 (2010).

30. M. Meyer, M. Kircher, M.-T. Gansauge, H. Li, F. Racimo, S. Mallick, J. G. Schraiber, F. Jay, K. Prüfer, C. de Filippo, P. H. Sudmant, C. Alkan, Q. Fu, R. Do, N. Rohland, A. Tandon, M. Siebauer, R. E. Green, K. Bryc, A. W. Briggs, U. Stenzel, J. Dabney, J. Shendure, J. Kitzman, M. F. Hammer, M. V. Shunkov, A. P. Derevianko, N. Patterson, A. M. Andrés, E. E. Eichler, M. Slatkin, D. Reich, J. Kelso, S. Pääbo, A high-coverage genome sequence from an archaic Denisovan individual. Science 338, 222-226 (2012).

31. T. Maricic, V. Günther, O. Georgiev, S. Gehre, M. Ćurlin, C. Schreiweis, R. Naumann, H. A. Burbano, M. Meyer, C. Lalueza-Fox, M. de la Rasilla, A. Rosas, S. Gajović, J. Kelso, W. Enard, W. Schaffner, S. Pääbo, A recent evolutionary change affects a regulatory element in the human FOXP2 gene. Mol. Biol. Evol. 30, 844-852 (2013).

32. K. Prüfer, F. Racimo, N. Patterson, F. Jay, S. Sankararaman, S. Sawyer, A. Heinze, G. Renaud, P. H. Sudmant, C. de Filippo, H. Li, S. Mallick, M. Dannemann, Q. Fu, M. Kircher, M. Kuhlwilm, M. Lachmann, M. Meyer, M. Ongyerth, M. Siebauer, C. Theunert, A. Tandon, P. Moorjani, J. Pickrell, J. C. Mullikin, S. H. Vohr, R. E. Green, I. Hellmann, P. L. F. Johnson, H. Blanche, H. Cann, J. O. Kitzman, J. Shendure, E. E. Eichler, E. S. Lein, T. E. Bakken, L. V. Golovanova, V. B. Doronichev, M. V. Shunkov, A. P. Derevianko, B. Viola, M. Slatkin, D. Reich, J. Kelso, S. Pääbo, The complete genome sequence of a Neanderthal from the Altai Mountains. Nature 505, 43-49 (2014).

33. S. Castellano, G. Parra, F. A. Sánchez-Quinto, F. Racimo, M. Kuhlwilm, M. Kircher, S. Sawyer Q. Fu, A. Heinze, B. Nickel, J. Dabney, M. Siebauer, L. White, H. A. Burbano, G. Renaud, U. Stenzel, C. Lalueza-Fox, M. de la Rasilla, A. Rosas, P. Rudan, D. Brajković, Ž. Kucan, 
I. Gušic, M. V. Shunkov, A. P. Derevianko, B. Viola, M. Meyer, J. Kelso, A. M. Andrés, S. Pääbo, Patterns of coding variation in the complete exomes of three Neandertals. Proc. Natl. Acad. Sci. U.S.A. 111, 6666-6671 (2014).

34. M. D. Gregory, J. S. Kippenhan, D. P. Eisenberg, P. D. Kohn, D. Dickinson, V. S. Mattay, Q. Chen, D. R. Weinberger, Z. S. Saad, K. F. Berman, Neanderthal-derived genetic variation shapes modern human cranium and brain. Sci. Rep. 7, 6308 (2017).

35. P. Gunz, P. Mitteroecker, F. L. Bookstein, in Modern Morphometrics in Physical Anthropology, D. E. Slice, Eds. (Kluwer Academic/Plenum Publishers, 2005), pp. 73-98.

36. P. Gunz, P. Mitteroecker, S. Neubauer, G. W. Weber, F. L. Bookstein, Principles for the virtual reconstruction of hominin crania. J. Hum. Evol. 57, 48-62 (2009).

37. P. Mitteroecker, P. Gunz, Advances in geometric morphometrics. Evol. Biol. 36, 235-247 (2009).

38. C. P. E. Zollikofer, M. S. Ponce de León, Virtual Reconstruction: A Primer in ComputerAssisted Paleontology and Biomedicine (Wiley-Interscience, 2005).

39. G. W. Weber, F. L. Bookstein, Virtual Anthropology: A Guide to a New Interdisciplinary Field (Springer, 2011).

40. R. L. Holloway, D. C. Broadfield, M. S. Yuan, The Human Fossil Record: Brain Endocasts-The Paleoneurological Evidence (Wiley-Liss, 2004).

41. R. Grün, J. S. Brink, N. A. Spooner, L. Taylor, C. B. Stringer, R. G. Franciscus, A. S. Murray, Direct dating of Florisbad hominid. Nature 382, 500-501 (1996).

42. J. D. Clark, Y. Beyene, G. WoldeGabriel, W. K. Hart, P. R. Renne, H. Gilbert, A. Defleur, G. Suwa, S. Katoh, K. R. Ludwig, J.-R. Boisserie, B. Asfaw, T. D. White, Stratigraphic, chronological and behavioural contexts of Pleistocene Homo sapiens from Middle Awash, Ethiopia. Nature 423, 747-752 (2003).

43. S. Neubauer, P. Gunz, in Digital Endocasts: From Skulls to Brains, E. Bruner, N. Ogihara, H. Tanabe, Eds. (Springer, 2018), pp. 173-190.

44. J. W. Gnadt, R. A. Andersen, Memory related motor planning activity in posterior parietal cortex of macaque. Exp. Brain Res. 70, 216-220 (1988).

45. R. A. Andersen, C. A. Buneo, Intentional maps in posterior parietal cortex. Annu. Rev. Neurosci. 25, 189-220 (2002).

46. S. Dehaene, M. Piazza, P. Pinel, L. Cohen, Three parietal circuits for number processing. Cogn. Neuropsychol. 20, 487-506 (2003).

47. G. Goldenberg, J. Spatt, The neural basis of tool use. Brain 132, 1645-1655 (2009).

48. S. Zhang, C.-s. R. Li, Functional connectivity mapping of the human precuneus by resting state fMRI. Neuroimage 59, 3548-3562 (2012).

49. E. Bruner, T. M. Preuss, X. Chen, J. K. Rilling, Evidence for expansion of the precuneus in human evolution. Brain Struct. Funct. 222, 1053-1060 (2017).

50. E. Bruner, H. Amano, J. M. de la Cuétara, N. Ogihara, The brain and the braincase: A spatial analysis on the midsagittal profile in adult humans. J. Anat. 227, 268-276 (2015).

51. E. Bruner, F. J. Román, J. M. de la Cuétara, M. Martin-Loeches, R. Colom, Cortical surface area and cortical thickness in the precuneus of adult humans. Neuroscience 286, 345-352 (2015).
52. C. J. Stoodley, E. M. Valera, J. D. Schmahmann, Functional topography of the cerebellum for motor and cognitive tasks: An fMRI study. Neuroimage 59, 1560-1570 (2012).

53. M. S. Salman, P. Tsai, The role of the pediatric cerebellum in motor functions, cognition, and behavior: A clinical perspective. Neuroimaging Clin. N. Am. 26, 317-329 (2016).

54. C. J. Stoodley, C. Limperopoulos, Structure-function relationships in the developing cerebellum: Evidence from early-life cerebellar injury and neurodevelopmental disorders. Semin. Fetal Neonatal Med. 21, 356-364 (2016).

55. A. A. Sokolov, R. C. Miall, R. B. Ivry, The cerebellum: Adaptive prediction for movement and cognition. Trends Cogn. Sci. 21, 313-332 (2017).

56. D. Holland, L. Chang, T. M. Ernst, M. Curran, S. D. Buchthal, D. Alicata, J. Skranes, H. Johansen, A. Hernandez, R. Yamakawa, J. M. Kuperman, A. M. Dale, Structural growth trajectories and rates of change in the first 3 months of infant brain development. JAMA Neurol. 71, 1266-1274 (2014).

57. H. Tiemeier, R. K. Lenroot, D. K. Greenstein, L. Tran, R. Pierson, J. N. Giedd, Cerebellum development during childhood and adolescence: A longitudinal morphometric MRI study. Neuroimage 49, 63-70 (2010).

58. T. D. Weaver, Did a discrete event $200,000-100,000$ years ago produce modern humans? J. Hum. Evol. 63, 121-126 (2012)

59. F. L. Bookstein, Landmark methods for forms without landmarks: Morphometrics of group differences in outline shape. Med. Image Anal. 1, 225-243 (1997).

Acknowledgments: We are grateful to three anonymous reviewers whose comments substantially improved this manuscript. We thank A. Balzeau, A. Barash, A. Ben-Ncer, M. A. El Hajraoui, C. Feja, M. Friess, F. Grine, I. Hershokovitz, A. Hoffmann, G. Koufos, O. Kullmer, D. Lieberman, S. Márquez, E. Mbua, A. McGinnis, D. Plotzki, Y. Rak, P. Ratiu, S. Raoui, C. Roeding, R. Schmitz, P. Schoenfeld, F. Schrenk, F. Spoor, J. Svoboda, H. Temming, M. Teschler-Nicola, B. Vandermeersch, G. W. Weber, and A. Winzer for access to specimens, help with CT scanning, and data processing. Funding: This research was funded by the Max Planck Society. Author contributions: S.N., P.G., and J.-J.H. designed the research and interpreted the results. S.N. performed the research and analyzed the data and wrote the paper with contributions from P.G. and J.-J.H. Competing interests: The authors declare that they have no competing interests. Data and materials availability: All data needed to evaluate the conclusions in the paper are present in the paper and/or the Supplementary Materials. All landmark data analyzed in this paper may be requested from the authors.

Submitted 7 August 2017

Accepted 19 December 2017

Published 24 January 2018

10.1126/sciadv.aao5961

Citation: S. Neubauer, J.-J. Hublin, P. Gunz, The evolution of modern human brain shape. Sci. Adv. 4, eaao5961 (2018). 


\section{ScienceAdvances}

\section{The evolution of modern human brain shape}

Simon Neubauer, Jean-Jacques Hublin and Philipp Gunz

Sci Adv 4 (1), eaao5961.

DOI: $10.1126 /$ sciadv.aao5961

ARTICLE TOOLS

SUPPLEMENTARY

MATERIALS

REFERENCES

PERMISSIONS http://advances.sciencemag.org/content/4/1/eaao5961

http://advances.sciencemag.org/content/suppl/2018/01/22/4.1.eaao5961.DC1

This article cites 54 articles, 9 of which you can access for free http://advances.sciencemag.org/content/4/1/eaao5961\#BIBL

http://www.sciencemag.org/help/reprints-and-permissions 